\title{
Validation of aerosol estimation in atmospheric correction algorithm ATCOR
}

\author{
B. Pflug ${ }^{\text {a, } *}$, M. Main-Knorn ${ }^{\mathrm{a}}$, A. Makarau ${ }^{\mathrm{b}}$, R. Richter ${ }^{\mathrm{b}}$ \\ ${ }^{\text {a }}$ German Aerospace Center (DLR), Earth Observation Center, Remote Sensing Technology Institute, Photogrammetry and Image \\ Analysis, 12489 Berlin, Germany - (Bringfried.Pflug, Magdalena.Main-Knorn)@dlr.de \\ ${ }^{\mathrm{b}}$ German Aerospace Center (DLR), Earth Observation Center, Remote Sensing Technology Institute, Photogrammetry and Image \\ Analysis, Oberpfaffenhofen, 82234 Weßling, Germany - (Aliaksei.Makarau, Rudolf.Richter)@dlr.de
}

SESSION: DATA-5, Data applications and quality assessment

KEY WORDS: Image processing, Atmospheric correction, ATCOR, validation, aerosol retrieval, RapidEye, Landsat

\begin{abstract}
:
Atmospheric correction of satellite images is necessary for many applications of remote sensing, i.e. computation of vegetation indices and biomass estimation. The first step in atmospheric correction is estimation of the actual aerosol properties. Due to the spatial and temporal variability of aerosol amount and type, this step becomes crucial for an accurate correction of satellite data. Consequently, the validation of aerosol estimation contributes to the validation of atmospheric correction algorithms. In this study we present the validation of aerosol estimation using own sun photometer measurements in Central Europe and measurements of AERONET-stations at different locations in the world. Our ground-based sun photometer measurements of vertical column aerosoloptical thickness (AOT) spectra are performed synchronously to overpasses of the satellites RapidEye, Landsat 5, Landsat 7 and Landsat 8 . Selected AERONET data are collocated to Landsat 8 overflights. The validation of the aerosol retrieval is conducted by a direct comparison of ground-measured AOT with satellite derived AOT using the ATCOR tool for the selected satellite images.

The mean uncertainty found in our experiments is $\Delta$ AOT $550 \mathrm{~nm} \approx 0.03 \pm 0.02$ for cloudless conditions with cloud + haze fraction below $1 \%$. This AOT uncertainty approximately corresponds to an uncertainty in surface albedo of $\Delta \rho \approx 0.003$. Inclusion of cloudy and hazy satellite images into the analysis results in mean $\triangle$ AOT $550 \mathrm{~nm} \approx 0.04 \pm 0.03$ for both RapidEye and Landsat imagery. About $1 / 3$ of samples perform with the AOT uncertainty better than 0.02 and about $2 / 3$ perform with AOT uncertainty better than 0.05 .
\end{abstract}

\section{INTRODUCTION}

Atmospheric correction of satellite data is required for many applications of remote sensing, like computation of vegetation indices, biomass estimation and plant health studies. It reduces effects of scattering and absorption by gases and aerosols in the atmosphere between the Earth's surface and the sensor and minimizes the influence of solar illumination and topography on the registered signal. However, application of atmospheric correction algorithms requires knowledge about the uncertainty of the correction process. This study provides an estimation of correction uncertainty of the atmospheric correction tool ATCOR (Richter, 1996, Richter et al., 2006) using groundbased sun photometer measurements. We used RapidEye and Landsat satellite data for comparative exercise.

Atmospheric correction includes correction of molecular absorption, molecular scattering and aerosol effects. The largest uncertainties for atmospheric correction procedures arise out of aerosol correction due to spatial and temporal variation of aerosol amount and type. Therefore, we investigate the uncertainty of atmospheric correction by validation of aerosol estimation. Kaufman et al. (1997) showed that an uncertainty in aerosol retrieval $\triangle$ AOT550nm is linked to an uncertainty in surface reflectance $\Delta \rho$ by the relation of:

$$
\Delta \rho=\Delta \text { AOT550nm } / 10 \text {. }
$$

In this study we make use of easy available and frequently used satellite data and widely known tools for their pre-processing to provide experimental estimates of uncertainty in aerosol-optical thickness (AOT) retrieval and thus surface reflectance calculation. Our findings may help to recognize the influence and assess the effects of atmospheric correction uncertainty for RapidEye and Landsat multispectral data for environmental applications.

\section{DATA}

\subsection{Test sites}

The proposed validation of atmospheric correction requires ground-based measurements of vertical column AOT-spectra synchronously to satellite overpasses. Validation is performed by direct comparison of aerosol retrieval from ATCOR with ground-based results.

Regional ground-based aerosol measurements were acquired synchronously to 30 overpasses of RapidEye, Landsat 5, Landsat 7 and Landsat 8 between 2001 and 2014. Test sites are located in Germany and at the Polish Baltic Sea coast (See Figure 1) and can be characterized by flat terrain with dense dark vegetation pixels existing in the images. A global dataset was obtained from AERONET data collocated with Landsat 8 images. 17 AERONET station around the world were selected for this analysis (Figure 1). One desert test-site located in AbuDhabi with no dense dark vegetation (DDV) pixels within the image was also included.

\footnotetext{
* Corresponding author.
} 


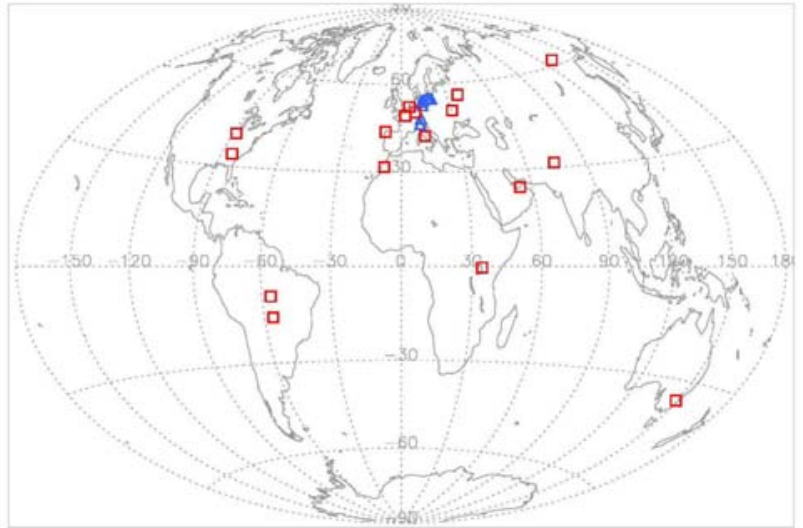

Figure 1. Location of test sites used for these investigations. Red squares mark locations of AERONET sites (global data set) and blue triangles mark locations of own sunphotometer measurements (regional data set).

\subsection{Satellite data}

Landsat satellites have observed Earth from space since 1972. Landsat 5 Thematic Mapper (TM) was launched in 1984 and was operational imaging until November 2011, for over 27 years (USGS, 2014a). TM had 6 spectral bands in the visible, near infrared, and short wave infrared portions of the spectrum and 1 thermal band. Currently, both Landsat 7 and Landsat 8 collect data. They were launched in 1999 and 2013 (USGS, $2014 b, 2014 c)$. Each of both satellites has a 16-day revisit cycle with an 8-day offset between Landsat 7 and Landsat 8 . Landsat 7 Enhanced Thematic Mapper Plus (ETM+) was constructed with the same bands like Landsat $5 \mathrm{TM}$ and an additional panchromatic band. One of the improved features of ETM + is the on-board calibration capability. The Landsat 8 payload consists of 2 sensors - the Operational Land Imager (OLI) and the Thermal Infrared Sensor (TIRS). OLI collects data in the heritage Landsat multispectral bands with refined bandwidth and improved radiometric performance. Additionally OLI has 2 new bands - one in the deep blue for coastal zone observations and one tailored especially for detecting cirrus clouds. All 3 Landsat satellites follow a near-polar, sunsynchronous orbit at a nominal altitude of $705 \mathrm{~km}$ covering the entire earth every 16 days. Common to all 3 Landsat sensors is also the swath width of $185 \mathrm{~km}$ resulting in scene size of $170 \mathrm{~km} \times 185 \mathrm{~km}$ with pixel size of $30 \mathrm{~m}$. Landsat Level-1 data products are geometrically and radiometrically corrected images.

RapidEye is a constellation of 5 satellites equipped with identical sensors and located in the same orbit plane (RapidEye AG, 2012). The satellites are equal distributed along sunsynchronous orbit in $630 \mathrm{~km}$ altitude. The RapidEye satellites have a revisit time of 5.5 days at nadir and a daily revisit capability with off-nadir observations. RapidEye's MultiSpectral Imager (MSI) sensors have 5 spectral bands (RapidEye $A G, 2012)$ in the visible to near-infrared spectral range with a swath width of $77 \mathrm{~km}$. Ground sampling distance of $6.5 \mathrm{~m}$ at nadir results in $5 \mathrm{~m}$ pixel size of the ortho-rectified images. This study is based on Level 3A tiles (RapidEye Ortho Product) provided with radiometric, sensor and geometric corrections. The size of RapidEye tiles is $25 \mathrm{~km}$ x $25 \mathrm{~km}$.

Figure 2 shows the distribution of Landsat and RapidEye spectral bands in the spectrum. The main difference between

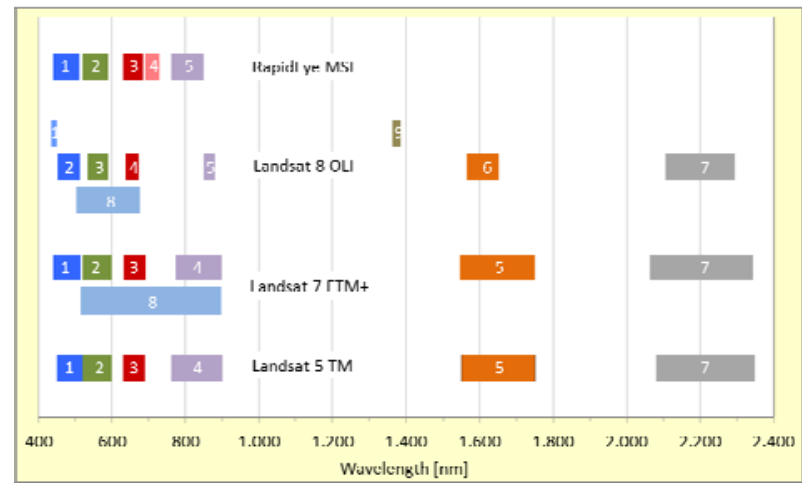

Figure 2. Spectral bands of RapidEye and Landsat sensors

the Landsat and RapidEye sensors with respect to atmospheric correction applications is the existence of a spectral band around $2.2 \mu \mathrm{m}$ for Landsat instruments.

\subsection{Sunphotometer data}

Ground-based measurements were performed with 2 Microtops II Instruments: an Ozonometer and a sunphotometer. Both instruments have a field of view angle of $2.5^{\circ}$. Channel specifications are given in Table 1. Radiation captured by collimators and bandpass filters radiates onto the photodiodes. Silicon photodetectors are used for the visible and near infrared (NIR) channels. In the first three channels GaP photodetectors (Gallium Phosphate) are used due to their sensitivity in the UV region, low noise level and low sensitivity above $500 \mathrm{~nm}$. Signals from the photodiodes are processed in series with 20 conversions per second so that results can be treated as if the photodiodes were read simultaneously.

\begin{tabular}{|c|c|}
\hline $\begin{array}{c}\text { Optical channels } \\
\text { Microtops Ozonometer }\end{array}$ & $\begin{array}{c}\text { Optical channels } \\
\text { Microtops Sunphotmeter }\end{array}$ \\
\hline $305.5 \pm 0.3 \mathrm{~nm} \quad$ FWHM $2 \mathrm{~nm}$ & $380 \pm 0.4 \mathrm{~nm} \quad$ FWHM $4 \mathrm{~nm}$ \\
\hline $312.5 \pm 0.3 \mathrm{~nm} \quad$ FWHM $2 \mathrm{~nm}$ & $440 \pm 1.5 \mathrm{~nm} \quad$ FWHM $10 \mathrm{~nm}$ \\
\hline $320.0 \pm 0.3 \mathrm{~nm} \quad$ FWHM $2 \mathrm{~nm}$ & $500 \pm 1.5 \mathrm{~nm} \quad$ FWHM $10 \mathrm{~nm}$ \\
\hline $936 \pm 1.5 \mathrm{~nm}$ FWHM $10 \mathrm{~nm}$ & $675 \pm 1.5 \mathrm{~nm} \quad$ FWHM $10 \mathrm{~nm}$ \\
\hline $1020 \pm 1.5 \mathrm{~nm}$ FWHM $10 \mathrm{~nm}$ & FWHM $10 \mathrm{~nm}$ \\
\hline
\end{tabular}

Table 1. Channel specifications of Microtops instruments

Measurements were performed at each time with both instruments in a close sequence; first few scans with one Microtops and immediately afterward few scans with the other. Thus, the data characterize the atmosphere at the same time and can be analyzed coupled. Measuring multiple scans with each instrument allows excluding some scans with imperfect orientation to the sun.

AERONET stations are equipped with CIMEL CE-318 instruments (Holben et.al., 1998). The CIMEL spectral radiometer is a robotically pointed sun and sky spectral radiometer with a $1.2^{\circ}$ full angle field of view. The instruments measure direct solar radiation and radiance of the solar aureole and the sky. Eight interference filters serve for spectral band selection between $340 \mathrm{~nm}$ and $1640 \mathrm{~nm}$. Standard bands are 440 $\mathrm{nm}, 670 \mathrm{~nm}, 870 \mathrm{~nm}, 940 \mathrm{~nm}$ and $1020 \mathrm{~nm}$. UV enhanced silicon detectors with sufficient signal-to-noise are used for spectral observations between $300 \mathrm{~nm}$ and $1020 \mathrm{~nm}$. Other detectors like InGAs are used for the longer wavelengths. A direct sun measurement for all 8 bands takes approximately 
$10 \mathrm{~s}$. Triplet observations of those scans are performed $30 \mathrm{~s}$ apart giving an opportunity for cloud screening of the data. Clouds cause an observable variation in the triplets due to the faster time variation of clouds. Triplet observations are made every 15 minutes over the day.

\section{DATA PROCESSING}

\subsection{Processing of satellite data}

ATCOR works with different algorithms for processing Landsat and RapidEye data. The algorithm for Landsat data is similar to that published by Kaufman for processing of MODIS data (Kaufman and Sendra, 1988; Kaufman et.al., 1997). Landsat data have a spectral channel around $2.2 \mu \mathrm{m}$, which can be easily used for detection of dense dark vegetation (DDV) pixels. The influence of aerosols at $2.2 \mu \mathrm{m}$ can be neglected and the signal measured at satellite can be interpreted as surface reflectance. Empirical correlations of reflectance of DDV-pixels between the shortwave infrared (SWIR) and the red band, and between the red and blue band are used for aerosol retrieval. RapidEye data cannot be processed with that algorithm, because of lack of SWIR channel. The algorithm applied for sensors like RapidEye relies on multiple thresholds for determination of DDV-pixels in the red part of the spectrum (Richter et.al., 2006) and uses only the empirical correlation between the red and blue band.

Atmospheric correction module ATCOR2 (software version $8.3 .1,2014)$ for flat terrain conditions was used for processing satellite data. Adjustable parameters had been set to variable aerosol optical thickness (visibility) over the scene, haze removal over land and no shadow removal. Haze removal is switches off automatically by ATCOR if the percentage of haze pixels is below $2 \%$. Rural aerosol type was selected with the atmospheric model corresponding to the latitude zone and season. Adjacency range was set to $1 \mathrm{~km}$ and number of adjacency zones to 1 .

Selection of rural (continental) aerosol type is generally a convenient choice for processing atmospheric correction with ATCOR. The selected aerosol type determines the initial wavelength behavior of the path radiance. ATCOR adapts the wavelength course of the path radiance to the current situation during processing. This adaptation provides spectral bands exist in the blue-to-red- region and the scene contains reference areas of known reflectance behavior. Both conditions are satisfied for the Landsat- and RapidEye satellite images under consideration, with exception of the AbuDhabi image. The fix choice of rural aerosol model was tested for part of the regional data set running ATCOR with three of the four aerosol type models available in ATCOR: maritime, rural, and urban. The aerosol model for desert condition is not representative for the regional test sites. Processing with maritime and rural aerosol models give nearly identical results in the visible/NIR. Urban aerosol type gives very different results, with lower agreement with the ground-truth data.

\subsection{Processing of sunphotmeter measurements}

Microtops sunphotometer measurements are processed using a coupled analysis of sunphotometer and ozonometer measurements (Pflug, 2013). First ozonometer data are used for computation of vertical column ozone content [cmSTP]. Actual vertical column ozone content is necessary for computation of vertical column AOT-spectra. AOT spectra allow computation of the vertical column Angstrœm exponent $\alpha$, which contains information about aerosol particle size and aerosol type. Spectral dependency of AOT given with the AOT-spectra is also used for computation of vertical column water vapor content [cm precipitable water column] and for interpolating the $\mathrm{AOT}$ at $550 \mathrm{~nm}$.

A fundamental component of the AERONET system is data processing with referenced and generally accepted processing algorithms (Holben et al., 1998). The algorithm used for retrieval of AOT from direct sun radiation measurements is described in detail in Shaw (1983). The AERONET Version 2 Direct Sun Algorithm makes use of satellite observations as input for $\mathrm{NO}_{2}$ and $\mathrm{O}_{3}$ total column concentrations (AERONET, 2008).

\section{RESULTS AND DISCUSSION}

\subsection{Results of Microtops-sunphotometer measurements}

Reliable ground-truth data are crucial precondition for accurate validation of atmospheric correction procedures. Compilation of the data set to be finally used for the validation therefore required a rigorous cloud screening of in-situ data. As a result 2 datasets collocated with satellite images were discarded from analysis.

The final, cloud-screened regional dataset contains 28 samples. 20 of these samples are located in the Potsdam/Berlin area and 6 are located at the Baltic Sea coast. The final regional dataset covers very low to high vertical column aerosol content (Figure 3). The in-situ AOT at $550 \mathrm{~nm}$ ranges from 0.05 to 0.28 with a mean value of 0.12 . With the global data set (AERONET) this range is extended to AOTmax of 0.42. The data set covers all seasons, mostly from spring to fall. It is representative for a wide variation of different solar zenith angles. More than $80 \%$ of the data samples have an Ångstrœmexponent above 1 , indicating the dominance of continental aerosols.

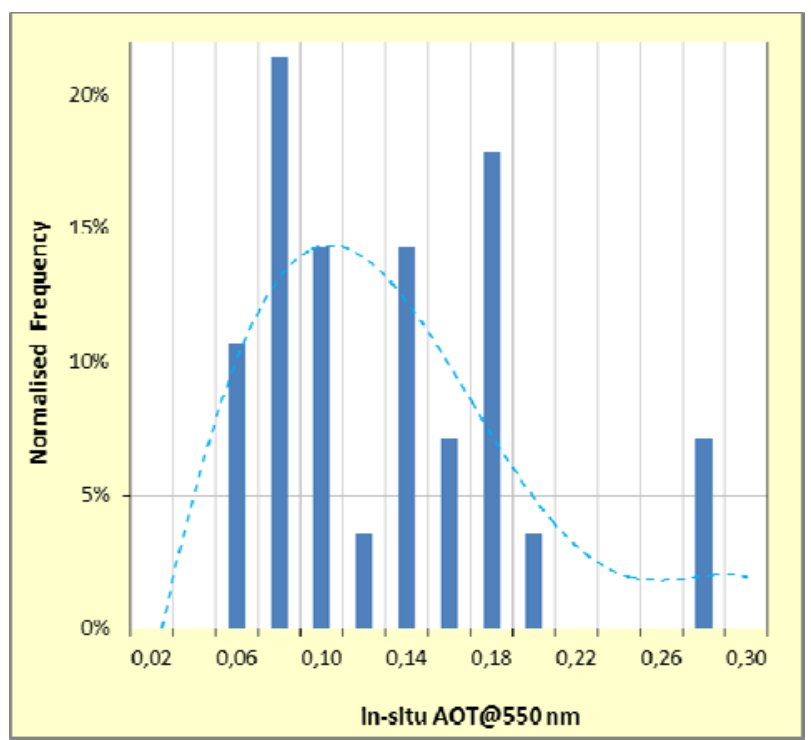

Figure 3. Frequency distribution of in-situ AOT at $550 \mathrm{~nm}$ computed from Microtops measurements. The dashed line is a polynomial fit through the data. 

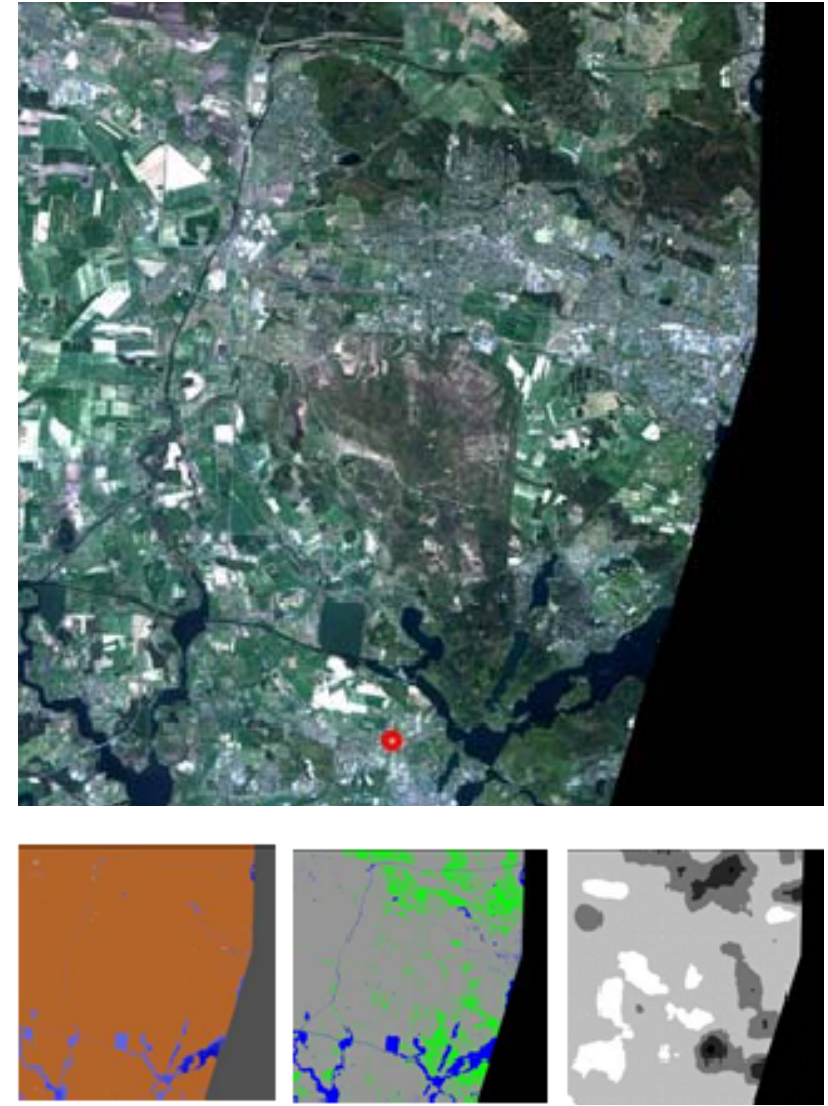

\subsection{Results of ATCOR processing}

ATCOR processing is applied for Landsat Level-1 products and RapidEye Level-3A tiles. These top-of-atmosphere (TOA) data are geometrically and radiometrically corrected. Main output of ATCOR is atmospherically corrected Bottom-of-atmosphere (BOA) reflectance for all sensor spectral bands. Optional outputs are a haze-cloud-water mask, an AOT image and a DDV classification image. DDV classification image shows the spatial distribution of DDV reference pixels classified for the AOT estimation.

One validation example for the RapidEye sensor is presented on Figure 4. The upper left image is a RGB-composite of Level-3A TOA data representing the input to ATCOR. Processing was executed with default settings (rural aerosol type and the fall/spring atmosphere). Fall/spring atmosphere was selected regarding the acquisition time in April. The upper right image represents the atmospherically corrected BOA output image of ATCOR. The haze/cloud/water mask at the lower left corner contains $0.1 \%$ cloudy (grey) and $5.1 \%$ water pixels (deep blue). ATCOR classified thin haze over water or sun glint for some lakes (light blue) for $4.2 \%$ of the pixels. Majority of the pixels were classified as land surface (orange), with $12.6 \%$ of DDV pixels (lower center, green) well distributed over the tile. Classified DDV pixels match forest areas in the image. AOT image at the lower right shows little variation of AOT over the tile from 0.28 (black) to 0.30 (white). Mean AOT within the $5 \times 5$ pixel vicinity of sunphotometer location (red circle) is 0.30 and mean AOT over the full tile is $0.29 \pm 0.005$. Ground-truth AOT from Microtops measurements is $0.27 \pm 0.002$. The Angstrœm-exponent of 1.66 indicates presence of continental aerosols.

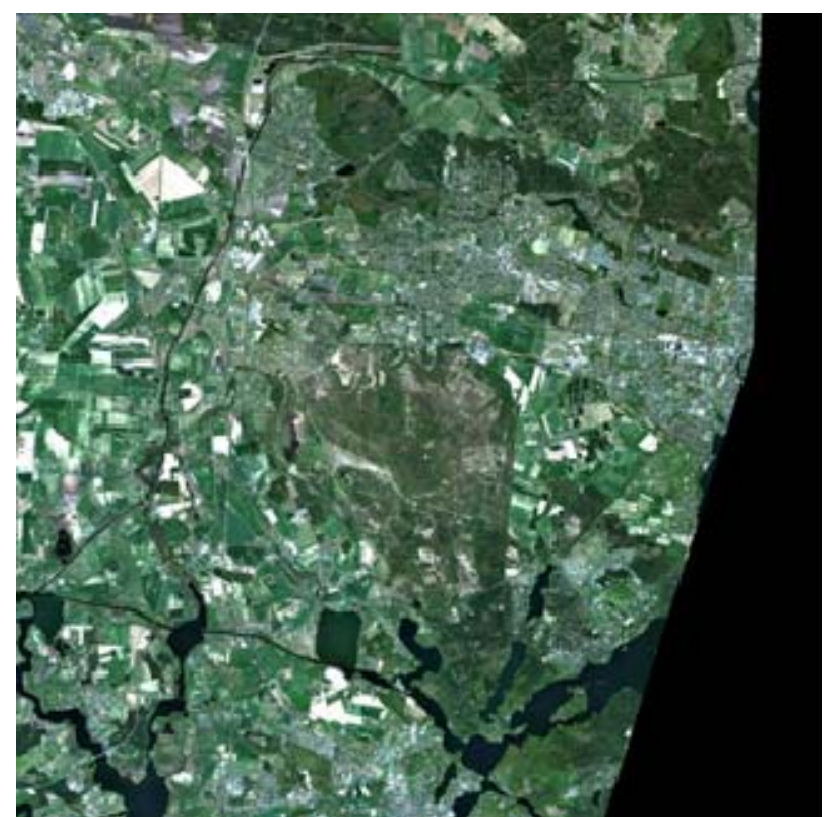

Figure 4. Example for processing RapidEye data

Upper left: RGB composite of input image (top of atmosphere) Red circle marks the sunphotometer location.

Upper right: RGB composite of corrected image (BOA)

Lower left: haze/cloud/water mask

Lower center: DDV classification map

Lower right: AOT-image

(Image over test site Potsdam, April 20, 2011)

\subsection{Comparison of ATCOR results with ground-truths}

4.3.1 AOT retrieval uncertainty for cloudless images of the regional data set is analyzed by comparison of AOT550 retrieved with ATCOR from satellite data with ground-truth values. Cloudless images are defined for this analysis by having cloud +haze cover below $1 \%$ in the ATCOR haze/cloud/water mask. Mean AOT over $3 \times 3$ Landsat pixels and over $5 \times 5$ RapidEye pixels around the location of sunphotometer measurements was used for the comparison exercise, shown in Table 2 and Figure 5.

Mean uncertainty of ATCOR aerosol retrieval for atmospheric correction is about $0.03 \pm 0.01$ for AOT at $550 \mathrm{~nm}$. This corresponds to uncertainty of surface reflectance of about 0.003 following equation (1). The trendline in Figure 5 indicates a tendency of ATCOR for overestimating AOT550 in very clear atmospheres and for underestimating AOT550 in turbid atmospheres.

\begin{tabular}{cccc}
\hline Landsat & $\begin{array}{c}\text { Number } \\
\text { of } \\
\text { samples }\end{array}$ & $\begin{array}{c}\text { Mean of } \\
\text { AOTdifferences }\end{array}$ & $\begin{array}{c}\text { Maximum of } \\
\text { AOTdifferences }\end{array}$ \\
\hline 7 ETM & 5 & $0.036 \pm 0.021$ & 0.072 \\
8 OLI TIRS & 3 & $0.046 \pm 0.037$ & 0.072 \\
\hline Rapid Eye & 8 & $0.029 \pm 0.008$ & 0.038 \\
\hline All together & 13 & $0.031 \pm 0.015$ & 0.043 \\
\hline
\end{tabular}

Table 2. AOT retrieval uncertainty $(\mathrm{NxN}$ area mean) for cloudless images of the regional data set. 


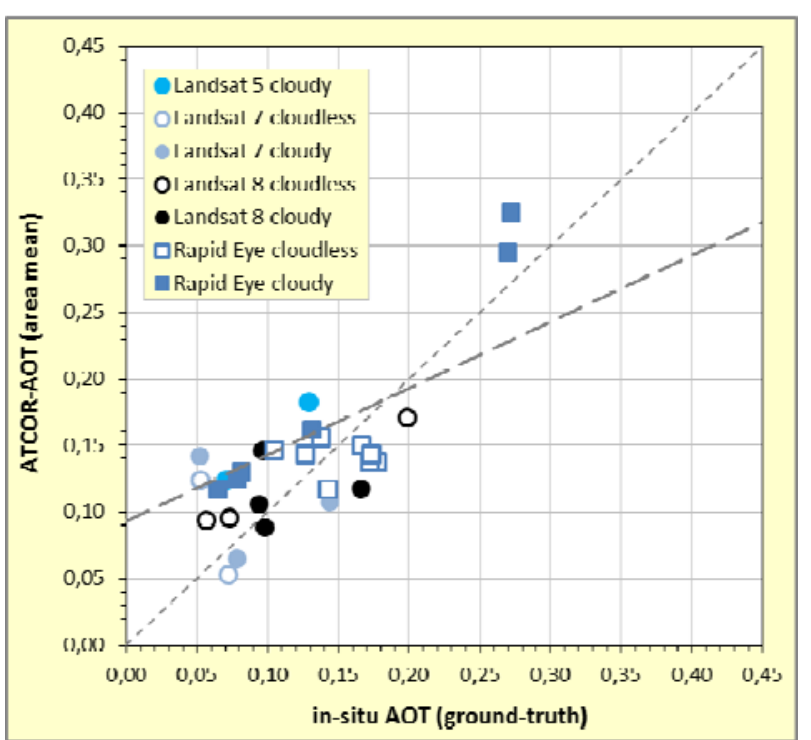

Figure 5. AOT estimated from satellite data using ATCOR compared with in situ-AOT for the regional data set.

The grey, long-dashed line is the linear trend through the data points.

Both Landsat 8 and RapidEye sensors perform similar good. Although Landsat and RapidEye data are processed with different algorithms within ATCOR, this gives evidence, that both algorithms provide equivalent results. The worse results for Landsat 7 may originate from the very low number of samples.

4.3.2 Mean of $\mathrm{NxN}$ pixel area compared with scene average: Next question addressed is about spatial variability of AOT over the satellite images. This is investigated on basis of ATCOR-AOT, which is the AOT estimated from satellite images using ATCOR. Figure 6 shows a plot of scene average ATCOR-AOT over area mean of $\mathrm{NxN}$ pixel vicinity around sunphotometer location. $\mathrm{NxN}$ is $5 \times 5$ pixels for RapidEye and $3 \times 3$ pixels for Landsat data. We found a good agreement between scene average and area mean, both for Landsat and

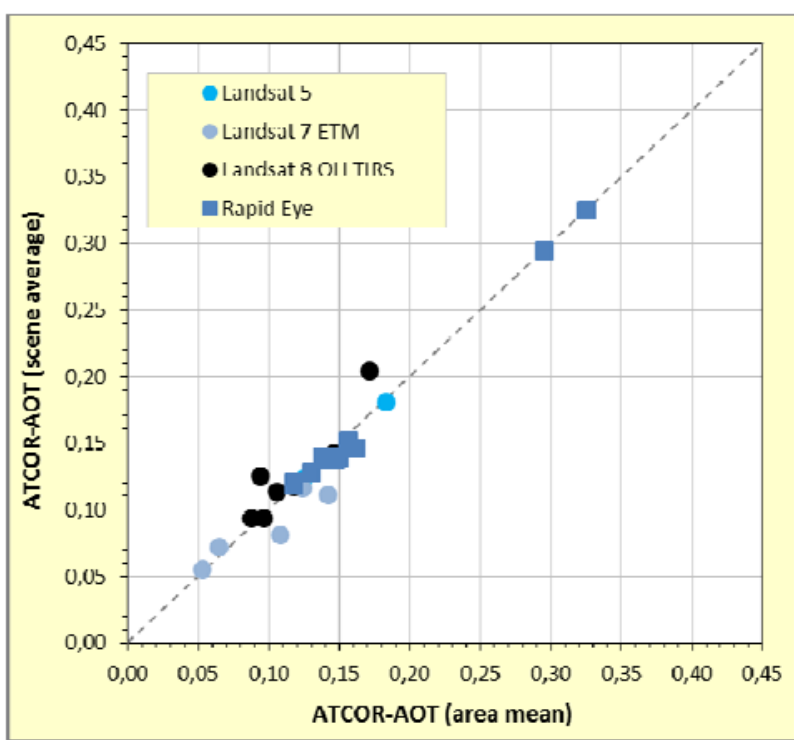

Figure 6. Scene average of ATCOR-AOT over area mean around sunphotometer location.
RapidEye sensors. As expectable, the agreement is better for RapidEye than for Landsat data due to the smaller area covered by RapidEye $(25 \mathrm{~km} \times 25 \mathrm{~km})$ satellite images.

Maximum AOT difference between area mean and scene average is 0.01 for RapidEye, which is significantly smaller than the AOT-difference to the ground-truth (Table 2). Therefore we presume that RapidEye data can be validated on basis of scene average AOT. This leads to the conclusion that single RapidEye tiles without haze resp. clouds can be processed with a fixed AOT.

Maximum AOT difference between area mean and scene average for Landsat is 0.03 , which is comparable with the ATCOR-AOT difference to the ground-truth (Table 2). Validation of Landsat data performed better for area mean than a full scene. Landsat images should be processed with variable AOT.

4.3.3 AOT retrieval uncertainty for cloudless images of the global data set: Global and regional data sets provide comparable results. Figure 7 indicates the same trend for global data as found for the regional data set (Figure 5). ATCOR is overestimating low turbidity and underestimating high turbidity. Mean uncertainty of ATCOR aerosol retrieval for Landsat 8 data and the global data set is about $0.04 \pm 0.03$ for AOT at $550 \mathrm{~nm}$. The uncertainty for the global data set is little higher than for the regional data set due to the occurrence of higher AOT-values. Processing desert image from AbuDhabi gives a large AOT-difference of 0.11 between ATCOR retrieval and ground-truth.

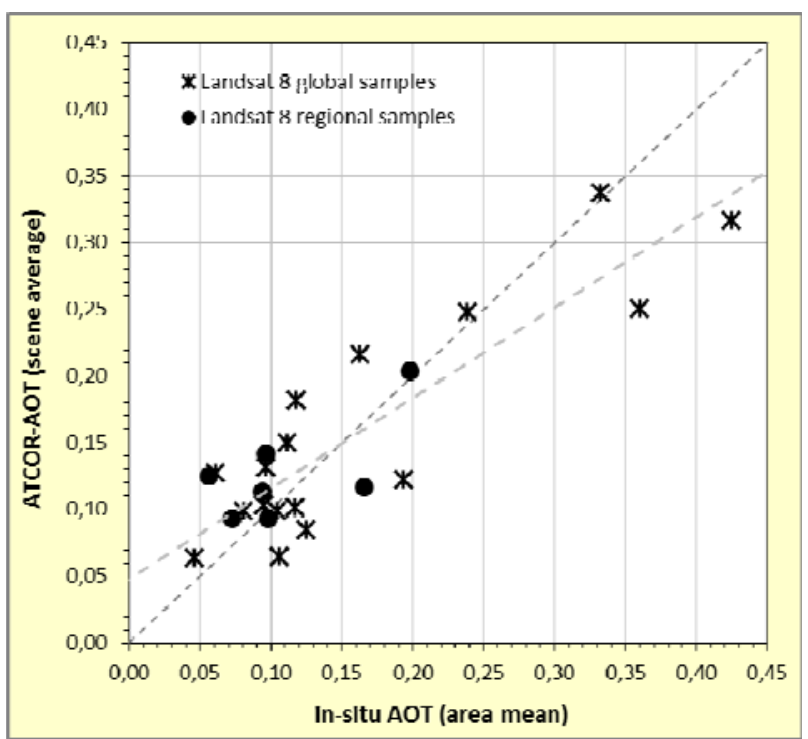

Figure 7. AOT estimated from satellite data using ATCOR compared with in situ-AOT for the global data set.

The grey, long-dashed line is the linear trend through the data points.

4.3.4 AOT retrieval uncertainty for cloudy images: Previous results are limited to conditions with cloud cover less than $1 \%$. Cloudless scenes are marked in Figure 5 with unfilled data points and data points with some clouds present in the images are filled. There are no remarkable differences in the processing results for cloudless and little cloudy images. Aerosol retrieval in ATCOR provides accurate results even with some clouds are present in the satellite image. 


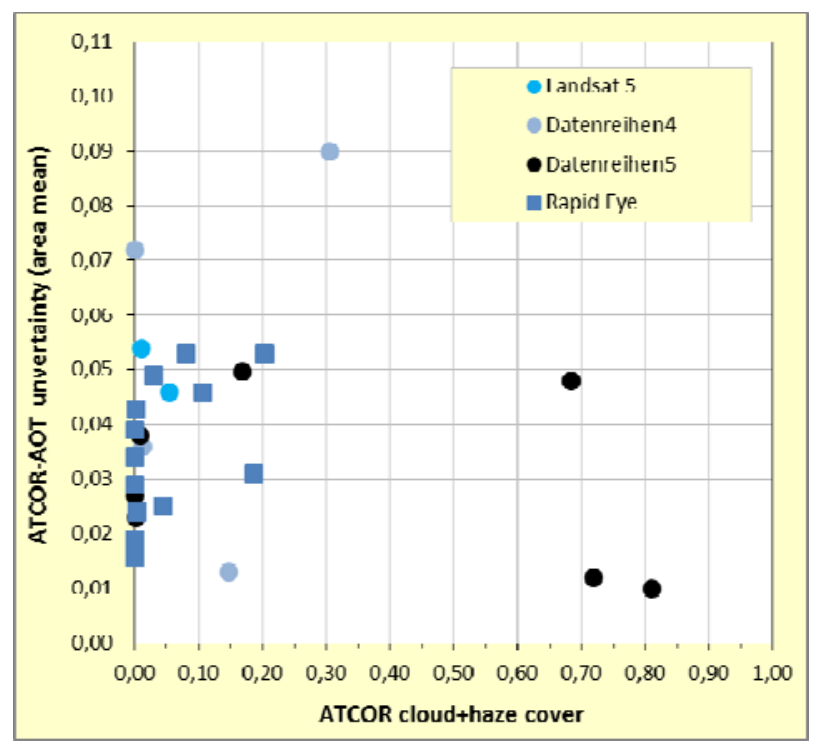

Figure 8. ATCOR-AOT estimation difference to ground-truth values as function of cloudiness.

\begin{tabular}{cccc}
\hline Landsat & $\begin{array}{c}\text { Number } \\
\text { of } \\
\text { samples }\end{array}$ & $\begin{array}{c}\text { Mean of } \\
\text { AOTdifferences }\end{array}$ & $\begin{array}{c}\text { Maximum of } \\
\text { AOTdifferences }\end{array}$ \\
\hline 5 TM & 31 & $0.040 \pm 0,029$ & 0.109 \\
\hline 7 ETM & 2 & $0.048 \pm 0.004$ & 0.051 \\
8 OLI TIRS & 24 & $0.042 \pm 0.028$ & 0.064 \\
\hline Rapid Eye & 14 & $0,035 \pm 0,018$ & 0,078 \\
\hline All together & 45 & $0,038 \pm 0,026$ & 0,109 \\
\hline
\end{tabular}

Table 3. AOT retrieval uncertainty for cloudless and cloudy images of the regional and global data set.

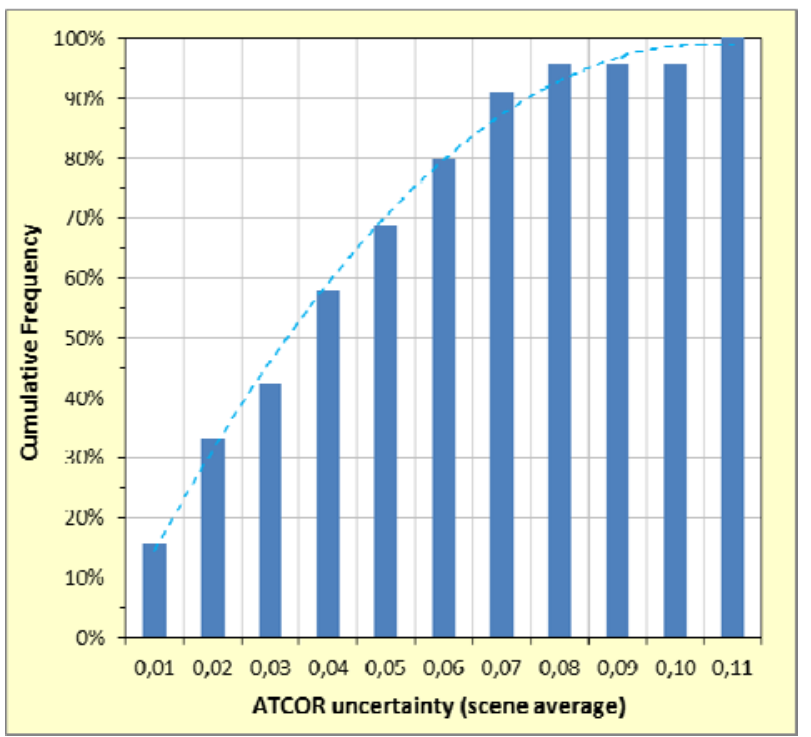

Figure 9. Cumulative frequency of ATCOR-AOT retrieval uncertainty.
Dependency of AOT uncertainty on cloudiness is plotted in Figure 8 . We found Landsat 8 images with up to $80 \%$ clouds providing excellent aerosol retrieval, if the test area around the sunphotometer is cloudless. Cloudless $20 \%$ of the Landsat images obviously can provide sufficient information for successful atmospheric correction processing.

Unfortunately, there is only one example of a dataset with images from 2 overpassing satellites at the same day and test site (September 6, 2011). The RapidEye image is covered by $11 \%$ clouds and haze and the Landsat 5 image by $6 \%$. Processing the Landsat 5 image and the RapidEye tile for this day gave identical results in the vicinity of the location of sunphotometer measurements. Mean AOT values over full images were not compared due to high cloud contamination over the RapidEye tile.

Finally, overall retrieval uncertainty is given in Table 3 . Mean AOT retrieval uncertainty both for cloudless and cloudy images is $0.04 \pm 0.03$ for $\mathrm{AOT}$ at $550 \mathrm{~nm}$. This corresponds to uncertainty of surface reflectance of about 0.004 following equation (1). Figure 9 shows that about $33 \%$ of the images are processed with aerosol retrieval uncertainty less or equal to 0.02 . AOT retrieval performs better than AOT uncertainty of 0.05 for about $70 \%$ of scenes. Only $10 \%$ of images are processed with AOT differences larger than 0.07 between ATCOR retrieval from satellite data and ground truth.

\section{SUMMARY AND CONCLUSIONS}

Atmospheric correction algorithm ATCOR was validated on the level of aerosol retrieval uncertainties for regional samples of test sites in middle Europe and a global test site with AERONET stations around the world. ATCOR has shown a very nice performance. Mean uncertainties of aerosol retrieval with ATCOR are $\triangle$ AOT550 $\approx 0.04$ corresponding approximately to surface reflectance uncertainty $\Delta \rho \approx 0.004$. ATCOR AOT retrieval shows a tendency for underestimating the AOT for high atmospheric turbidity and overestimating for low turbidity. Landsat and RapidEye data are processed with different algorithms within ATCOR. Both algorithms are working precise and comparable. Aerosol retrieval in ATCOR provides accurate results even with some clouds present in the satellite image. More satellite overpasses synchronous to atmospheric ground-truth measurements would allow performing a more detailed and significant statistical analysis.

The present study is limited to validation of aerosol estimation, which is a crucial issue for validation of atmospheric correction. Additional studies to validate surface reflectance and other processes and effects in atmospheric correction are required and forthcoming.

\section{ACKNOWLEDGEMENTS}

We sincerely thank BlackBridge AG for providing data from the RapidEye Science Archive (RESA) and USGS for providing Landsat data. We thank Tymon Zielinski from the IOPAS for assistance organizing the measurements at the Polish Baltic Sea Coast and we thank Helge Witt for performing some of the Microtops measurements. We thank the PIs and their staff for establishing and maintaining the AERONET sites used in this investigation. 


\section{REFERENCES}

AERONET, 2008. http://aeronet.gsfc.nasa.gov/new_web/ Documents/version2_table.pdf

Holben, B.N., Eck, T.F., Slutsker, I.,Tanré, D., Buis, J.P., Setzer, A., Vermote, E., Reagan, J.A., Kaufman, Y.J., Nakajima, T., Lavenu, F., Jankowiak, I., Smirnov, A., 1998. AERONET-A Federated Instrument Network and Data Archive for Aerosol Characterization. Remote Sensing of Environment 66(1), pp. 1-16

Kaufman, Y. and Sendra, C., 1988. Algorithm for automatic atmospheric corrections to visible and near-IR satellite imagery. International Journal of Remote Sensing 9(8), pp. 1357-1381.

Kaufman, Y. J., Wald, A. E., Remer, L.A., Gao, BC., Li, RR.

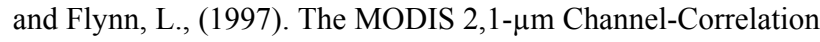
with Visible Reflectance for Use in Remote Sensing of Aerosol. IEEE Transactions on Geoscience and Remote Sensing 35(5), pp. 1286-1298

Pflug, B., (2013). Ground based measurements of aerosol properties using Microtops instruments. AIP Conf. Proc. 1531, pp. 588-591;

doi: 10.1063/1.4804838, http://dx.doi.org/10.1063/1.4804838

RapidEye AG, 2012. Satellite Imagery Product Specifications, Version 4.1, September 2012, Brandenburg, Germany

Richter, R., 1996. A spatially adaptive fast atmospheric correction algorithm. International Journal of Remote Sensing 17(6), pp. 1201-1214;

http://dx.doi.org/10.1080/01431169608949077

Richter, R., Schläpfer, D. and Müller, A., 2006. An automatic atmospheric correction algorithm for visible / NIR imagery. International Journal of Remote Sensing 27(10), pp. 20772085; doi:10.1080/01431160500486690

Shaw, G.E., 1983. Sun photometry. Bull. Am. Meteorol. Soc. 64(1), pp. 4-11

USGS, 2014a. U.S.Geological Survey. http://landsat.usgs.gov/about_landsat5.php

USGS, 2014b. U.S.Geological Survey. http://landsat.usgs.gov/about_landsat5.php

USGS, 2014c. U.S.Geological Survey. http://landsat.usgs.gov/about_ldcm.php 